\title{
On The Possibility to Trace Frozen Curd in Buffalo Mozzarella Cheese
}

\author{
Nadia Manzo ${ }^{1}$, Loredana Biondi ${ }^{2}$, Donatella Nava ${ }^{2}$, Federico Capuano $^{2}$, Fabiana Pizzolongo ${ }^{1}$, Alberto Fiore $^{3} \&$ \\ Raffaele Romano ${ }^{1}$ \\ ${ }^{1}$ Dept. of Agricultural Sciences, University of Naples Federico II, Portici (NA), Italy \\ ${ }^{2}$ Istituto Zooprofilattico Sperimentale Del Mezzogiorno, Portici (NA), Italy \\ ${ }^{3}$ School of Science, Engineering \& Technology Division of Food \& Drink, Abertay University, Dundee, UK \\ Correspondence: Raffaele Romano, University of Naples Federico II, Portici (NA), Italy. Tel: 08-1253-9358. \\ E-mail: rafroman@unina.it
}

Received: September 17, 2016

Accepted: December 29, $2016 \quad$ Online Published: January 13, 2017

doi:10.5539/jfr.v6n1p104

URL: http://dx.doi.org/10.5539/jfr.v6n1p104

\begin{abstract}
The manufacturing of Buffalo Mozzarella PDO (Protected Designation of Origin) cheese requires the exclusive use of fresh buffalo milk, which must be transformed into cheese within 60 hours after milking. The limited availability of buffalo milk and simultaneous increase in Mozzarella demand during the summer cause producers to use frozen intermediates (milk and/or curd) in the cheese-making process. These practices are not allowed. Few data are available in the literature about the effects of freezing on buffalo milk and curd. Recent studies demonstrated that the use of frozen buffalo milk can be detected in mozzarella cheese based on the increase in casein fragment $\gamma 4-\mathrm{CN}$. This work aims to verify the possibility of tracing the presence of frozen curd in Buffalo Mozzarella PDO cheese. The electrophoresis technique was used to reveal the presence of $\gamma 4-\mathrm{CN}$. Equivalent concentrations of this fragment were found in fresh and frozen curd that were stored for 9 months. Our results suggest that $\gamma 4-\mathrm{CN}$ cannot be used to discriminate fresh PDO Mozzarella and Mozzarella cheese produced from frozen curd. A second objective of the work was to evaluate the effects of freezing on curd lipids. In particular, the fatty acid and mono-diglyceride profiles were evaluated. Significant differences were found in the amounts of 1,2-Dipalmitin and 1,3-Diolein between fresh curd and curd that was stored for 9 months at freezing temperatures. Although some significant differences were found in the mono-diglyceride profiles, no objective marker that can distinguish between fresh and frozen products is currently available.
\end{abstract}

Keywords: Buffalo mozzarella cheese, curd, diglycerides, freezing, $\gamma_{4}-\mathrm{CN}$, PDO

\section{Introduction}

Buffalo Mozzarella PDO (Protected Designation of Origin) is a stretched curd cheese produced exclusively by using fresh buffalo milk, which must be processed within 60 hours after milking (EC Regulation 103/2008). The final product must satisfy certain criteria, such as a white porcelain colour, fat/dry matter $\geq 52 \%$ (w/w) and maximum moisture content of $65 \%(\mathrm{w} / \mathrm{w})$.

Geographical Indications are the authentic expression of the values and the history of a territory. These certifications are a guarantee of quality for both producers and consumers, in terms of safety, genuineness and freshness.

Mozzarella cheese is a widespread product: in the year 2014, 38,000 tons of Mozzarella PDO cheese were produced (data obtained from the Consortium for the Protection of Buffalo Mozzarella PDO cheese). During the summer there is limited availability of buffalo milk and a concurrent increase in Mozzarella demand. To overcome this inconvenience, producers resort not to contemplated practices. In particular, they freeze milk or curd (mainly curd) in the winter and use them to manufacture Mozzarella PDO when there is a lack of fresh milk. Moreover, some producers buy frozen curd from foreign countries at low costs and mix it with the local curd to produce PDO cheese. Therefore, food control authorities require an analytical method to discriminate between fresh Mozzarella PDO cheese and Mozzarella produced from frozen intermediates, which are not produced according to the PDO manufacturing process.

Some authors examined the effects on proteolysis, lipolysis and sensory characteristics of the frozen curd 
addition in cheeses obtained from bovine, goat and sheep species (Alonso, Picon, Gaya \& Nuñez, 2013; Picon, Alonso, Gaya, \& Nuñez, 2013; Pazzola et al., 2013; Van Hekken, Tunick \& Park, 2005; Todaro, Scatassa, Alicata, Mazza \& Caracappa, 2011; Zhang, Mustafa, Ng-Kwai-Hang \& Zhao, 2006). In particular, according to Zhang et al. (2006), good quality sheep cheese can be produced from ovine milk that is frozen at -15 and $-25^{\circ} \mathrm{C}$ for 6 months without affecting the cheese yield or composition. Pazzola et al. (2013) suggest that considerable decreasing renneting properties for sheep milk after a long-freezing storage can be obtained, which implies that the freezing of milk should be limited to periods shorter than 5 months. Todaro et al., (2011) reported different effects of freezing according to the species, for example goat milk is more affected by the length of the freezing period and the typology of defrosting than ovine and bovine milk. Van Hekken, Tunick \& Park (2005) found no significant proteolysis during the refrigerated ageing of soft cheese.

Little data is available in the literature about the effects of freezing buffalo milk or curd. Therefore, finding a method that enables the identification of frozen curd use in the Buffalo Mozzarella PDO cheese-making process is an important goal to protect this high-value product.

Di Luccia et al. (2009) identified a casein fragment $(\gamma 4-\mathrm{CN})$, which is derived from the action of plasmin on $\beta$-casein (Ismail \& Nielsen, 2010), as a marker of frozen milk in Buffalo Mozzarella PDO cheese. This fragment was detected as a faint band in fresh milk, and an increase of its intensity was observed when the milk freezing time was prolonged $\left(-20^{\circ} \mathrm{C}\right.$ for 12 months). Moreover, recently, a fragment derived from $\alpha \mathrm{S} 1$-casein $(\alpha \mathrm{S} 1-\mathrm{I})$ was also suggested as a possible indicator of frozen curd in Buffalo Mozzarella cheese (Petrella et al., 2015), even if the thermal and time histories of the analysed mozzarella cheeses remained unknown in this study.

Mainly, commercial fraud regards use of frozen curd rather than frozen milk, as curd storage is cheaper and easier, requiring smaller spaces and lower energy costs. In this study, the effectiveness of $\gamma 4$-CN to identify frozen curd in Buffalo Mozzarella PDO cheese was evaluated. Then the effects of freezing on the lipid component, which is a possible index of oxidation phenomena, were studied to verify possible modifications that occur during the buffalo curd storage.

\section{Methods}

\subsection{Sampling}

The following samples were collected during Buffalo Mozzarella cheese-making process in three different dairy plants in province of Caserta, Salerno and Napoli (Campania region, Italy):

- Raw milk (RM);

- $\quad$ Thermized milk (TM);

- $\quad$ Premature curd (PC), with $\mathrm{pH}$ 6.2-6.3;

- $\quad$ Mature curd (MC), with pH 5.0-4.8;

- Mozzarella cheese (M).

Three different samplings were performed in each dairy plant to obtain a total of $9 \mathrm{RM}, 9 \mathrm{TM}, 9 \mathrm{PC}, 9 \mathrm{MC}$ and 9M samples.

The quality and hygiene parameters were tested to examine the sample's conformity to the current legislation. In particular, a microbiological analysis was performed to study and count the main pathogenic, spoilage and pro-technological bacteria. Then, chemical determinations, such as $\mathrm{pH}, \mathrm{Aw}$ and somatic cells were performed (data not shown).

Each sample was divided into 10 aliquots: the first was used to analyse the fresh product, and the other 9 aliquots were frozen at $-20^{\circ} \mathrm{C}$ (freezing time: 4 hours) for a total period of 9 months. Monthly, the samples were thawed, and caseins and fat were extracted for the analysis of casein and lipids.

To simulate, in the laboratory, the actual condition of dairy plants, a fast freezing was obtained by cutting curd and mozzarella samples to small sizes, nearly $100 \mathrm{~g}$, and freezing them at $-25^{\circ} \mathrm{C}$. The thawing process was conducted by maintaining the frozen samples at $4^{\circ} \mathrm{C}$ over-night, and subsequently in a water bath at $40^{\circ} \mathrm{C}$. After thawing, they were used for chemical analysis.

The freezing and thawing time-temperature profiles were registered using a data logger (Ebro), which was placed in the core of the sample. Temperature was measured at regular intervals of $30 \mathrm{sec}$.

\subsection{Quality And Hygiene Parameters}

The $\mathrm{pH}$ analysis was performed with a FIVE Easy ${ }^{\mathrm{TM}} \mathrm{pH}$-metre .

The water activity was measured by The Official Methods ISO 21807:200 at $25^{\circ} \mathrm{C} \pm 1{ }^{\circ} \mathrm{C}$, with Aqualab $4 \mathrm{TE}$ 
instrument.

The somatic cells were revealed through a fluorescence microscope Nucleo Counter SCC-109 - ASTORI according to the Internal Method. This method involves adding a DNA intercalator solution ( $500 \mu \mathrm{l})$ to $500 \mu \mathrm{l}$ of milk. The number of somatic cells was automatically calculated by a software program. The value of this parameter in accordance to Italian law (Regulation 853/2004) for buffalo milk is $\leq 400,000 *$ for $\mathrm{ml}$ (*rolling geometric average, which was calculated over a period of three months with at least one sample per month from bulk milk, unless otherwise specified by the appropriate authorities).

The total bacterial count was in accordance with UNI EN ISO 4833-1:2013. The legal limit is $\leq 1500,000 \mathrm{CFU} /$ $\mathrm{ml}$ or $\mathrm{g}$ at $30^{\circ} \mathrm{C}$ (rolling geometric average, which was calculated over a period of two months with at least two samplings per month), in accordance with Regulation n ${ }^{\circ} 853 / 2004$.

Microbiological analysis showed all parameters within legal limits (data not shown)

\subsection{Casein Extraction and $\gamma 4-C N$ Analysis}

Casein was separated from fresh and frozen curd by isoelectric precipitation at $\mathrm{pH} 4.6$ by addition of acetic acid.

The casein analysis was performed using the Official Method N. L74/25 of 20.03.1992, SDS-PAGE (Sodium Dodecyl Sulphate - PolyAcrylamide Gel Electrophoresis), and a subsequent densitometric analysis (GS-800 Bio-Rad).

\subsection{Lipid Extraction}

Lipids were extracted using the modified Schimith-Bondzynsky-Ratzlaff method (Official Method of Cheese Analysis (D.M.1986)).

\subsection{Fatty Acid Profile}

The fatty acid profile was analysed by using gas chromatography coupled with an FID detector (Agilent Technologies 6850 SeriesII). The GC was equipped with a capillary column 50\% CyanopropilMethil Silicone, $100 \mathrm{~m} 0.25 \mathrm{~mm}$ ID $0.20 \mu \mathrm{m}$. The oven program temperature was: $140^{\circ} \mathrm{C}$ x $5 \mathrm{~min}$, increase $4^{\circ} \mathrm{C} / \mathrm{min}$ until reaching $175^{\circ} \mathrm{C}$ for $20 \mathrm{~min}$, then increase $3^{\circ} \mathrm{C} / \mathrm{min}$ until reaching $240^{\circ} \mathrm{C}$ and maintained for $1 \mathrm{~min}$. The injector program temperature was: $60^{\circ} \mathrm{C} \times 0.1 \mathrm{~min}$, with an increase of $500^{\circ} \mathrm{C} / \mathrm{min}$ until reaching $260^{\circ} \mathrm{C}$ and maintained for $5 \mathrm{~min}$. Helium was used as the carrier gas (flow rate $1.8 \mathrm{ml} / \mathrm{min}$ ). The detector temperature was set at $260^{\circ} \mathrm{C}$.

A fat solution of $5 \%$ in hexane was injected, after transesterification with $2 \mathrm{~N} \mathrm{KOH}$. Identification was performed with a 37 component FAME mix standard from Supelco, St.Louis, Mo, USA.

\subsection{Lipolitic Index}

To avoid the interference of triglycerides (TG) with mono and di-glycerides (MDG), the extracted fat from the fresh and frozen samples was separated using the SPE column, according to a modified procedure described in Caboni, M.F., Menotta, S., \& Lercker, G. (1996)..

The MDG fraction was analysed by gas chromatography coupled with mass spectrometry (GC MS), using a capillary column DB-5, 25m x $0.247 \mathrm{~mm}$ I.D., film thickness $0.25 \mu \mathrm{m}$. Betulin was used as an internal standard. The samples were analysed as trimethylsilyl (TMS) derivatives. As reported by other authors, NIST and Wiley libraries do not provide the mass spectra for all products of glycerol esterification. In particular, there is no single mass spectrum of diglycerides with different substitutes (Isidorov et al., 2007).

For the quantification, we assumed that all monoglycerides had an identical response factor as monoolein, and all diglycerides had an identical response factor as 1,2 diolein, which were used as external standards.

\subsection{Statistical Analysis}

All experiments were performed in triplicate and results are the average values of three determinations. The data were analysed by ANOVA XL-STAT.

\section{Results and Discussion}

Milk and curd used in the cheese-making process showed quality and hygiene parameters within the limits provided by the current legislation.

The raw and thermized milk showed a $\mathrm{pH}$ of 6.6-6.8.

The somatic cell values were within the limits indicated by Reg. EC 853/2004; values ranged from 167,000 to 281,000 .

The total bacterial count (TBC) ranged between 6.3 and $4.5 \log$ CFU/ml $\mathrm{g}$ in RM and TM. 


\subsection{Evaluation of the Г4-CN Effectiveness in Frozen Curd}

The SDS-PAGE electrophoretic profiles were obtained for premature curd, mature curd and mozzarella cheese in their fresh and frozen states. The casein profiles of premature and mature curd are shown in figure 1 and 2.

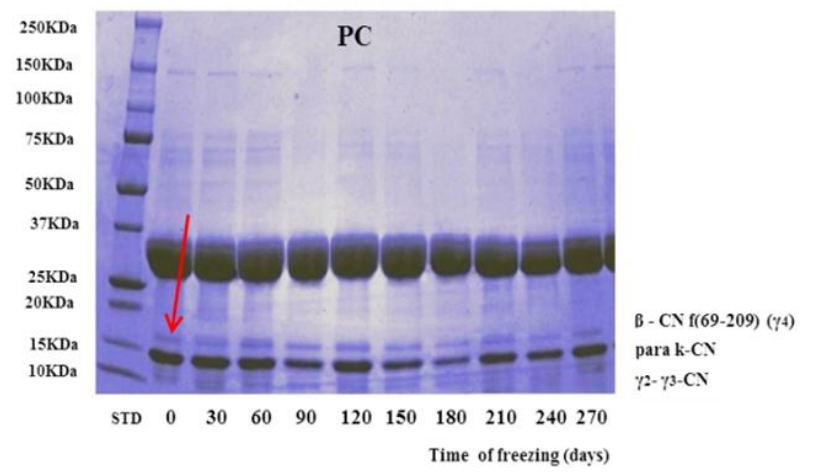

Figure 1. Polyacrylamide gel Electrophoresis (Sds-Page) Of premature curd (PC) at different freezing times

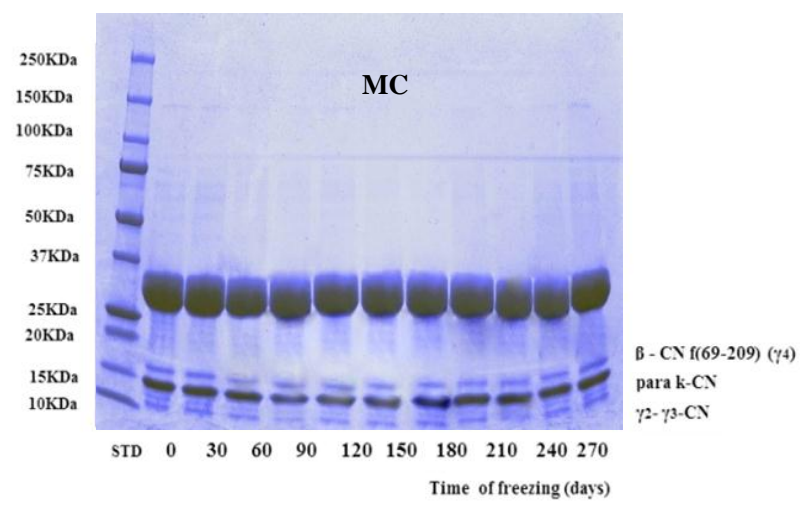

Figure 2. Polyacrylamide gel electrophoresis (SDS-PAGE) of mature curd (MC) at different freezing times

The first lane of the gel shows the standard protein (STD) with molecular weights from $10 \mathrm{kDa}$ to $250 \mathrm{kDa}$. In the second lane the electrophoretic profile of fresh sample is shown. The frozen profiles, from 30 to 270 days, can be observed in the following lanes.

The profiles of premature curd, mature curd and mozzarella (data not shown) had four electrophoretic bands: $\gamma 4-\mathrm{CN}, \gamma 2-\mathrm{CN}, \gamma 3-\mathrm{CN}$ and para-k-CN. The first three fragments are derived from the hydrolysis of $\beta$-casein by the action of plasmin (Ismail \& Nielsen, 2010).

Our results show that the fragment $\gamma 4-\mathrm{CN}$ is a band of identical intensity in all analysed samples (both fresh and frozen at different freezing times). The densitometric analysis confirmed that no significant differences $(p>0.05)$ were found between fresh and frozen samples.

Di Luccia et al. 2009 reported an increase in $\gamma 4-\mathrm{CN}$ intensity in refrigerated and frozen buffalo milk.

This discordant result can be explained by the proteolytic action of plasmin on $\beta$-casein, which appears more or less intense depending on many factors, such as the process conditions, animal health, phase and number of lactations (Burbrink \& Hayes, 2006). Our samples showed quality and hygiene parameters within the limits provided by the current legislation.

\subsection{Fatty Acid Profile}

Fatty acids from C4 to C22 were detected in all samples. In figure 3, the fresh and frozen (9 months) fatty acid profiles of mature curd overlaid. Concentration of saturated fatty acids (approximately $70 \%$ ), monounsaturated fatty acids (approximately 26\%) and polyunsaturated fatty acids (3\%) were found. Only the main fatty acids are reported in the figure. 


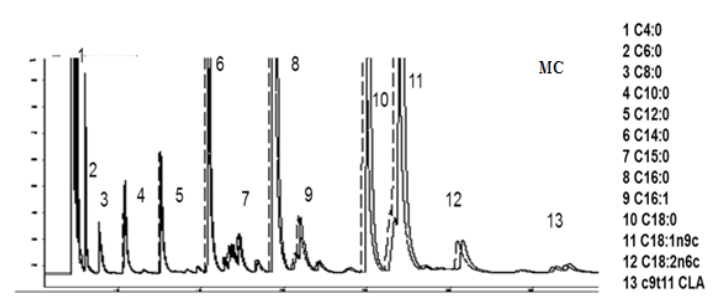

Figure 3. Fatty acids profile of mature curd (MC) in fresh samples (continuous line) and samples that were frozen for 270 days (dot line)

As observed and confirmed by the statistical analysis, no significant differences $(p>0.05)$ between the fresh and frozen fatty acid profiles were detected. The complete list of fatty acids identified in fresh and frozen curd ( 9 months) is reported in table 1 .

Table 1. Fatty acid composition ( $\mathrm{g} / 100 \mathrm{~g}$ ) of fresh $(\mathrm{t} 0)$ and frozen mature curd $(\mathrm{t} 9)$ (mean values \pm standard deviations)

\begin{tabular}{lll}
\hline $\mathrm{FA}$ & $\mathrm{t} 0$ & $\mathrm{t} 9$ \\
\hline $\mathrm{C} 4: 0$ & $2.04 \pm 0.09$ & $2.42 \pm 0.16$ \\
$\mathrm{C} 6: 0$ & $1.98 \pm 0.05$ & $2.21 \pm 0.07$ \\
$\mathrm{C} 8: 0$ & $1.02 \pm 0.02$ & $1.15 \pm 0.10$ \\
$\mathrm{C} 10: 0$ & $2.03 \pm 0.01$ & $2.26 \pm 0.18$ \\
$\mathrm{C} 11: 0$ & $0.09 \pm 0.01$ & $0.09 \pm 0.01$ \\
$\mathrm{C} 12: 0$ & $2.51 \pm 0.01$ & $2.69 \pm 0.18$ \\
$\mathrm{C} 13: 0$ & $0.10 \pm 0.00$ & $0.10 \pm 0.01$ \\
$\mathrm{C} 14: 0$ & $10.47 \pm 0.10$ & $10.97 \pm 0.54$ \\
$\mathrm{C} 14: 1$ & $0.84 \pm 0.00$ & $0.88 \pm 0.06$ \\
$\mathrm{C} 15: 0$ & $1.06 \pm 0.01$ & $1.09 \pm 0.04$ \\
$\mathrm{C} 16: 0$ & $34.49 \pm 0.35$ & $34.75 \pm 0.21$ \\
$\mathrm{C} 16: 1$ & $1.23 \pm 0.01$ & $1.24 \pm 0.02$ \\
$\mathrm{C} 17: 0$ & $0.97 \pm 0.01$ & $1.09 \pm 0.01$ \\
$\mathrm{C} 17: 1$ & $0.44 \pm 0.01$ & $0.46 \pm 0.01$ \\
$\mathrm{C} 18: 0$ & $13.11 \pm 0.13$ & $12.17 \pm 0.75$ \\
$\mathrm{C} 18: 1 \mathrm{n} 9 \mathrm{t}$ & $1.45 \pm 0.00$ & $1.34 \pm 0.00$ \\
$\mathrm{C} 18: 1 \mathrm{n} 9 \mathrm{c}$ & $22.04 \pm 0.38$ & $21.35 \pm 0.58$ \\
$\mathrm{C} 18: 2 \mathrm{n} 6 \mathrm{t}$ & $0.13 \pm 0.00$ & $0.11 \pm 0.01$ \\
$\mathrm{C} 18: 2 \mathrm{n} 6 \mathrm{c}$ & $2.43 \pm 0.06$ & $2.28 \pm 0.06$ \\
$\mathrm{C} 20: 0$ & $0.29 \pm 0.01$ & $0.24 \pm 0.04$ \\
$\mathrm{C} 20: 1$ & $0.57 \pm 0.02$ & $0.54 \pm 0.02$ \\
$\mathrm{c} 9 \mathrm{t} 11 \mathrm{CLA}$ & $0.20 \pm 0.01$ & $0.20 \pm 0.01$ \\
$\mathrm{C} 18: 3 \mathrm{n} 3$ & $0.02 \pm 0.00$ & $0.02 \pm 0.01$ \\
$\mathrm{C} 20: 2$ & $0.02 \pm 0.00$ & $0.02 \pm 0.01$ \\
$\mathrm{C} 20: 3 \mathrm{n} 3$ & $0.09 \pm 0.00$ & $0.04 \pm 0.00$ \\
$\mathrm{C} 20: 4 \mathrm{n} 6$ & $0.08 \pm 0.01$ & $0.04 \pm 0.01$ \\
$\mathrm{C} 20: 5 \mathrm{n} 3$ & $0.06 \pm 0.00$ & $0.04 \pm 0.01$ \\
$\mathrm{C} 22: 6 \mathrm{n} 3$ & $0.05 \pm 0.00$ & $0.03 \pm 0.01$ \\
$\mathrm{C} 22: 0$ & $0.15 \pm 0.00$ & $0.12 \pm 0.02$ \\
$\mathrm{C} 22: 2$ & $0.03 \pm 0.00$ & $0.02 \pm 0.01$ \\
\hline$(\mathrm{p}>0.05)$ & &
\end{tabular}

Our results of fatty acid profiles are consistent with those of Zhang, Mustafa, Ng-Kwai-Hang \& Zhao (2006) for sheep milk, where no effect on the milk or cheese fatty acid concentrations was found after the freezing storage. 


\subsection{Lipolitic Index}

Mono-diglycerides (MDG) were examined as an index of lipolitic activity becouse the lipases can attack the globules of milk fat, release free fatty acids and form mono- and diglycerides from triglycerides (TG) (Metha, 2015). According to Bareth, Strohmar \& Kitzelmann, (2003) if the sample contains fat, the diglycerides detection can be interfered by the presence of triglycerides and fatty acids from $\mathrm{C} 4$ to $\mathrm{C} 14$ and diglycerides cannot be cromatographically separated. To avoid these possible interferences, TG and phospholipids (P) were separated by solid phase extraction (SPE). No significant difference between fresh and frozen mature curd was detected. The MDG qualitative profiles for fresh and frozen curd after a period of 9 months were identical. After a freezing period of 9 months, an increase of 5.2\% and 8.5\% was revealed for 1,2-Dipalmitin and 1,3-Diolein, respectively. However, the obtained results cannot be considered markers of freezing storage.

The quantification results of MDG, TG and P in mature curd showed no significant differences between fresh and frozen samples. The results are shown in table 2 .

Table 2. \% Composition in TG, MDG and $\mathrm{P}$ of fat extracted by fresh ( $\mathrm{t} 0$ ) and frozen ( $\mathrm{t} 9$ ) mature curd (MC). Mean values \pm standard deviation

\begin{tabular}{cccc}
\hline & TG & MDG & P \\
\hline MC- t0 & $95.9 \pm 0.6$ & $4.0 \pm 0.6$ & $0.2 \pm 0.0$ \\
MC- t9 & $95.8 \pm 0.5$ & $3.9 \pm 0.6$ & $0.3 \pm 0.1$ \\
\hline
\end{tabular}

No statistical significant difference in the same column $(\mathrm{p}<0.05)$

In figure 4, the MDG profiles of fresh and frozen mature curd are reported.

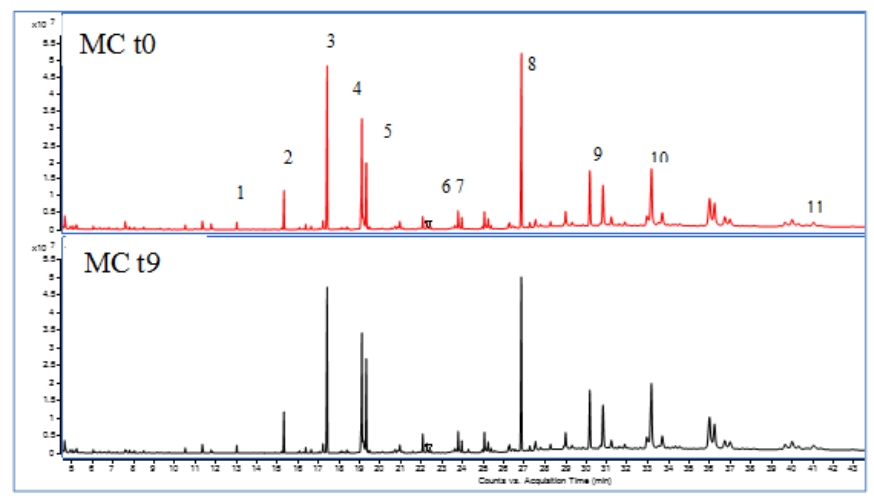

Figure 4. Fresh (t0) and frozen ( 9 months) mature curd MDG profile

Note 1. Decanoic acid, TMS derivative; 2:Myristic acid, TMS derivative; 3: Palmitic acid, TMS derivative; 4:Oleic acid, TMS derivative; 5:Stearic acid, TMS derivative; 6:1-Monoolein, 2TMS derivative; 7: 1-Monopalmitin, 2TMS derivative; 8: Cholesterol, TMS derivative; 9 : Internal standard (betulin); 10:1,2-Dipalmitin, TMS derivative; 11: 1,3-Dipalmitin, TMS derivative

Among the identified molecules, significant differences were detected for 1,2-Dipalmitin and 1,3-Diolein between fresh and the frozen curd. In table 3, the detected amounts are reported.

Table 3. 1, 2-Dipalmitin and 1,3-Diolein content in fresh and frozen curd (9 months). The results are reported as \% of total MDG (average values \pm standard deviations)

\begin{tabular}{lcc}
\cline { 2 - 3 } & \multicolumn{3}{c}{ fresh } & frozen \\
\cline { 2 - 4 } 1,2-Dipalmitin & $3.61^{\mathrm{a}} \pm 0.04$ & $3.80^{\mathrm{b}} \pm 0.06$ \\
1,3-Diolein & $1.17^{\mathrm{a}} \pm 0.01$ & $1.27^{\mathrm{b}} \pm 0.01$ \\
\hline
\end{tabular}

a-b: Different letters in the same row correspond to statistical significant differences $(\mathrm{p}<0.05)$ 


\section{Conclusion}

The obtained casein detection results confirmed the non-effectiveness of $\gamma 4-\mathrm{CN}$ to discriminate mozzarella cheese produced by frozen curd. When curd was maintained at freezing temperatures for 9 months, no significant difference was found in the $\gamma 4-\mathrm{CN}$ content compared to the fresh samples.

Therefore, the identified marker in the scientific literature (higher in frozen milk than in fresh milk) is not effective when frozen curd is used. In our study, no increase in $\gamma 4-\mathrm{CN}$ was observed during the freezing time, thus false negative cases can be created when a high content of $\gamma 4-\mathrm{CN}$ is detected in Mozzarella cheese.

Regarding MDG, an increase in 1,2-Dipalmitin and 1,3-Diolein was found. However, the obtained results suggest that it is currently not possible to discriminate PDO Mozzarella cheese produced from frozen curd because of the lack of an objective marker.

The effects of freezing on the rheological properties of Buffalo Mozzarella PDO cheese produced from frozen curd will be evaluated.

\section{Acknowledgments}

This research has been supported by the Ministry of Healt (IZSME 02/13 RC)

\section{References}

Alonso, R., Picon, A., Gaya, P., \& Nuñez, M. (2013). Proteolysis, lipolysis, volatile compounds and sensory characteristics of Hispánico cheeses made using frozen curd from raw and pasteurized ewe milk. J. Dairy Res., 80, 51-57. http://dx.doi.org/10.1017/S0022029912000738

Bareth, A., Strohmar, W., \& Kitzelmann, E. (2003). Gas cromatographic determination of mono-and diglycerides in milk and milk products. Eur Food Res Technol, 216, 365-368. http://dx.doi.org/10.1007/s00217-002-0650-7

Burbrink, C. N., \& Hayes, K. D. (2006). Effect of thermal treatment on the activation of bovine plasminogen. Int. Dairy J., 16, 580-585. http://dx.doi.org/10.1016/j.idairyj.2005.08.017

Caboni, M. F., Menotta, S., \& Lercker, G. (1996). Separation and analysis of phospholipids in different foods with a Light-Scattering Detector. J. Am. Oil Chem. Soc., 73, 1561-1566. http://dx.doi.org/10.1007/bf02523525

Di Luccia, A., Picariello, G., Trani, A., Alviti, G., Loizzo, P., Faccia, M., \& Addeo, F. (2009). Occurrence of $\beta$-casein fragments in cold-stored and curdled river buffalo (Bubalus bubalis L.) milk. J. Dairy Sci., 92, 1319-1329. http://dx.doi.org/10.3168/jds.2008-1220

Isidorov, V.A., Rusak, M., Szczepaniak, L., \& Witkowski, S. (2007). Gas chromatographic retention indices of trimethylsilyl derivatives of mono- and diglycerides on capillary columns with non-polar stationary phases. Journal of Chromatography A., 1166, 207-211. http://dx.doi.org/10.1016/j.chroma.2007.07.047

Ismail, B., \& Nielsen, S. S. (2010). Plasmin protease in milk: current knowledge and relevance to dairy industry. J. Dairy Sci., 93, 4999-5009.

Metha, B. M. (2015). Chemical Composition of Milk and Milk Products. Handbook of Food Chemistry. http://dx.doi.org/10.1007/978-3-642-36605-5_31

Petrella, G., Pati, S., Gagliardi, R., Rizzuti, A., Mastrorilli, P., La Gatta, B., \& Di Luccia, A. (2009). Study of proteolysis in river buffalo mozzarella cheese using a proteomics approach. Journal of Dairy Science, 98, 7560-7572. http://dx.doi.org/10.3168/jds.2015-9732

Pazzola, M., Dettori, M. L., Piras, G., Pira, E., Manca, F., Puggioni, O., Noce, A., \& Vacca, G. M. (2013). The Effect of Long-term Freezing on Renneting Properties of Sarda Sheep Milk. Agriculturae Conspectus Scientificus, 78, 275-279 http://hrcak.srce.hr/106922

Picon, A., Alonso, R., Gaya, P., \& Nuñez, M. (2013). High-pressure treatment and freezing of raw goat milk curd for cheese manufacture: effects on cheese characteristics. Food Bioprocess Technol, 6, 2820-2830. http://dx.doi.org/10.1007/s11947-012-0923-5

Reg. CE 103/2008, recante approvazione delle modifiche non secondarie del disciplinare di una denominazione registrata nel registro delle denominazioni d'origine protette e delle indicazioni geografiche protette Mozzarella di Bufala Campana (DOP)

Todaro, M., Scatassa, M. L., Alicata, M. L., Mazza, F., \& Caracappa, S. (2011). Latte bovino, ovino e caprino congelato: variazione dei parametri fisici, chimici e tecnologici. Scienza e Tecnica Lattiero-Casearia, 62, 
275-281. http://hdl.handle.net/10447/61639

Van Hekken, D. L., Tunick, M. H., \& Park, Y. W. (2005) Effect of frozen storage on the proteolytic and rheological properties of soft caprine milk cheese. J. Dairy Sci., 88, 1966-1972. http://dx.doi.org/10.3168/jds.S0022-0302(05)72872-1

Zhang, R. H., Mustafa, A. F., Ng-Kwai-Hang, K. F., \& Zhao, X. (2006). Effects of freezing on composition and fatty acid profiles of sheep milk and cheese. Small Ruminant Res., 64, 203-210. http://dx.doi.org/10.1016/j.smallrumres.2005.04.025

\section{Copyrights}

Copyright for this article is retained by the author(s), with first publication rights granted to the journal.

This is an open-access article distributed under the terms and conditions of the Creative Commons Attribution license (http://creativecommons.org/licenses/by/4.0/). 